\title{
Identification and Evaluation of Antibacterial Compounds from the Vibrio sp. associated with the Ascidian Pycnoclavella diminuta
}

\author{
Abdurraafi' Maududi Dermawan ${ }^{1 *}$, Elin Julianti ${ }^{1}$, Masteria Yunovilsa Putra ${ }^{2}$, \\ Firmansyah Karim² \\ ${ }^{1}$ School of Pharmacy, Bandung Institute of Technology, Bandung, West Java, Indonesia \\ ${ }^{2}$ Research Center for Oceanography, Indonesian Institute of Sciences, Jakarta, Indonesia
}

ARTICLE HISTORY

Received: September 2019

Revised: November 2019

Accepted: December 2019

*Corresponding author

Email: rafi.derma@gmail.com

\begin{abstract}
This study aims to obtain secondary metabolites that have antibacterial activity from bacteria endophytic of ascidian Pycnoclavella diminuta collected from the coast of Bitung, North Sulawesi, Indonesia. The research was started with screening antibacterial activity of six bacteria isolated from $P$. diminuta. The active bacteria were selected for identification using standard biological molecular method and further fermentation to produce secondary metabolites. The isolation of secondary metabolites was conducted by various chromatography method and then selected fraction was based on the antibacterial activity from bioautography results. The result showed that the active isolate by coding M2.Tnk.Bt $5.10^{-3} .2$ was identified as Vibrio sp. The potential active fraction was further sub-fractionated by HPLC semi-preparative and each of these sub-fractions was tested against Staphylococcus aureus, Bacillus cereus, Enterococcus faecalis, Eschericia coli, and Vibrio cholerae. The test results showed that all 17 sub-fractions were active against Gram-positive bacteria $S$. aureus and B. cereus, and only one sub-fraction (SFr 2) showed antibacterial activity against E. faecalis. Whereas in Gram-negative bacteria, 2 sub-fractions (SFr 12 and SFr 13) showed antibacterial activity against $E$. coli and 12 sub-fractions active against $V$. cholerae. GC-MS analysis of the SFr 2 sub-fraction showed the presence of fifteen phytochemical constituents with a major compound Pyrrolo [1,2-a] pyrazine-1,4-dione, hexahydro-3- (2 methylpropyl).
\end{abstract}

Keywords: Vibrio sp.; Pycnoclavella diminuta; antibacterial compounds

\section{INTRODUCTION}

Infectious diseases caused by microorganisms continue to increase every year and become a challenge faced by the global community (Smith et al., 2014). The rising number of infectious diseases is caused by the evolution of microbial pathogens that are resistant to existing antibiotics (Lupetti et al., 2002). The emergence of widespread resistant bacteria has led researchers to explore new alternative antibacterial agents from natural sources to be developed as new drugs (Walsh, 2003; Viejo-Diaz et al., 2005).

Recently, marine ecosystems have attracted attention as a potential new source for natural bioactive compounds (Kjer et al., 2010). The oceans, which cover more than $70 \%$ of our planet's surface with all its uniqueness and biodiversity, consist of abundant types of microbes (Bugni \& Ireland, 2004; König et al., 2006). Marine microorganisms have demonstrated the diversity of secondary metabolites that can be produced. Many new secondary metabolites have been reported with a wide range of biological activity. The extreme conditions resulted from competition between bacteria in the marine environment arise due to harsh chemical and physical environmental conditions, adaptation to different habitats and environments with high levels of stress, such as cold temperature, high pressure and little/no light, that cause these microorganisms naturally required to synthesize secondary metabolites that can be used as a weapon of defense and competition (Nikapitiya, 2012; Zheng et al., 2005). Therefore, marine creatures are prospective to produce a variety of new compounds with unique structural and chemical properties with higher biological activity than terrestrial creatures, so that they have a huge potential for the pharmaceutical industry (Nikapitiya, 2012).

Ascidian or tunicata is of one of the marine invertebrates from which thousands of metabolites have been successfully isolated and it produces many bioactive compounds with various bioactivity. Several studies have proven that some secondary metabolites isolated from ascidian are of symbiotic microorganism origin 
(Davidson, 1993; Schmidt \& Donia, 2010). Several findings on the secondary metabolites have shown a wide range of biological activity from ascidian-associated marine microorganisms including the activity as an antibacterial agent (Wyche et al., 2012; Ellis et al., 2014).

The marine biodiversity off the coastlines of Indonesia's many islands offers a tremendous opportunity to investigate potential antimicrobial compounds from both the marine invertebrates and the microorganisms that they carry (Putra et al., 2016a; Putra et al., 2016 b). Nonetheless, information on pharmacological activities from Indonesian ascidians and associated microorganisms is still limited. Here, we report a study on secondary metabolites produced from a species of Vibrio that is associated with the ascidian Pycnoclavella diminuta collected from the coast of Bitung in North Sulawesi, Indonesia.

\section{METHODS}

\section{Sample Collection}

Strain M2.Tnk.Bt $5.10^{-3} .2$ was isolated from ascidian Pycnoclavella diminuta collected from the coast of Bitung, North Sulawesi, Indonesia at a depth of 5-10 $\mathrm{m}$ by SCUBA diving. It has been deposited in the strain collection of Research Center for Oceanography, Indonesian Institute of Sciences, Indonesia.

\section{Identification of the Bacteria Strain}

Strain identification was carried out by molecular taxonomy using $16 \mathrm{~S}$ rRNA gene sequencing. A single colony was sub-cultured in Marine Broth at $29{ }^{\circ} \mathrm{C}$ for $48 \mathrm{~h}$. Genomic DNA was extracted following the protocol described by Presto ${ }^{\mathrm{TM}}$ Mini gDNA Bacteria Kit (Geneaid Biotech Ltd). Amplification of the 16S rRNA was performed using MyTaq Red Mix (Bioline) with specific primers 27F: AGAGTTTGATCMTGGCTCAG and 1492R: TACGGYTACCTTGTTACGACTT. Polymerase chain reaction was performed in a $25 \mu \mathrm{L}$ mix reaction containing $9.5 \mu \mathrm{L}$ dd $\mathrm{H}_{2} \mathrm{O}, 12.5 \mu \mathrm{L} 2 \mathrm{x}$ MyTaq Red Mix, $20 \mu \mathrm{mol} / \mu \mathrm{L}$ 27F Primer, $20 \mu \mathrm{mol} / \mu \mathrm{L}$ 1492R Primer and DNA Template. The PCR condition as follows 35 cycles of $95{ }^{\circ} \mathrm{C}$ for $15 \mathrm{~s}$ (denaturation), $52{ }^{\circ} \mathrm{C}$ for $15 \mathrm{~s}$ (annealing), $68{ }^{\circ} \mathrm{C}$ for $45 \mathrm{~s}$ (extension). PCR products purification with Zymoclean ${ }^{\mathrm{TM}}$ Gel DNA Recovery Kit (Zymo Research). The resulting sequence was then analyzed using BLAST and compared with nucleotide on the National Center for Biotechnology Information (NCBI) database.

\section{Cultivation, Extraction, and Isolation}

A seed culture of the strain M2.Tnk.Bt 5.10-3.2 was prepared by inoculation of $50 \mathrm{~mL}$ medium (starch 20 $\mathrm{g}$, glucose (Merck) $10 \mathrm{~g}$, peptone $5 \mathrm{~g}$, yeast extract 5 $\mathrm{g}$ and $\mathrm{CaCO}_{3}$ (Merck) $5 \mathrm{~g}$ in 1 liter seawater) in a 100
$\mathrm{mL}$ Erlenmeyer flask in a shaker $\left(29^{\circ} \mathrm{C} / 150 \mathrm{rpm}\right)$ for 24 h. This seed culture $(10 \mathrm{~mL}$ each) was then transferred to ten $2 \mathrm{~L}$ Erlenmeyer flask containing $1 \mathrm{~L}$ with same medium and cultured with shaking $(150 \mathrm{rpm})$ for 4 days at $29{ }^{\circ} \mathrm{C}$. The fermentation broth was extracted using ethyl acetate and the extract was concentrated by evaporation. The ethyl acetate extract was fractionated by vacuum liquid chromatography using on a silica gel column with elution performed on a gradient system of increasing polarity from n-hexane to EtOAc to Acetone to $\mathrm{MeOH}$. Each fraction was collected and evaporated for bioautography assay. The active fraction was further subjected to HPLC semi-preparative using isocratic elution with acetonitrile: $\mathrm{H}_{2} \mathrm{O}(35: 65)$ (flow rate $2 \mathrm{~mL}$ / min, Agilent C18 (10 x $250 \mathrm{~mm}), \mathrm{UV}-\mathrm{Vis}$ at $254 \mathrm{~nm})$. The different fractions were collected and concentrated by evaporation. The concentrated fractions were tested for antibacterial assay to identify the active fraction.

\section{Antibacterial Activity Assay}

\section{Bioautography}

Antibacterial activity of the fraction was carried out using the bioautography technique as previously described by Valle Jr et al. (2016) with slight modifications. The fractions were spotted on the $\mathrm{GF}_{254}$ silica gel TLC plate and eluted with three different eluent systems as follows: FA (n-heksan: $\left.\mathrm{CHCl}_{3}, 3,5: 1,5\right), \mathrm{FB}\left(\mathrm{CHCl}_{3}\right.$ :Acetone; 4:1), $\mathrm{FC}$ and $\mathrm{FD}\left(\mathrm{CHCl}_{3}: \mathrm{MeOH} ; 4,5: 1,5\right)$. Then, the TLC plate was observed under UV light at 254 wavelengths to determine the separation profile of each fraction. Furthermore, the TLC plate was placed aseptically to the media which had previously been inoculated with the bacteria tested (Staphylococcus aureus ATCC 6538 and Eschericia coli ATCC 8739) for 60 minutes so that the active compound on the TLC plate was transferred by diffusion into the media. Then, the TLC plate was removed and the agar plate was incubated at $37{ }^{\circ} \mathrm{C}$ for 18-24 h. The growth inhibition zones were observed and compared with TLC plate $\mathrm{R}_{f}$ value result.

\section{Agar diffusion method}

The sub-fraction results were conducted using agar diffusion method (CLSI, 2012). The bacteria tested (Staphylococcus aureus ATCC 6538, Bacillus cereus ATCC 11778, Enterococcus faecalis, Eschericia coli ATCC 8739 and Vibrio cholerae) were prepared by turbidimetry using UV-Vis spectrophotometer at a wavelength of $625 \mathrm{~nm}$ to obtain absorbance between $0.08-0.12$, which is equivalent to the standard 0.5 McFarland solution, and inoculated in sterile petri dish by streaking the cotton swab sterile on the surface of the MHA (Mueller-Hinton Agar) media. The procedure was repeated by rotating the petri dish up to $60^{\circ}$ to the bacterial suspension evenly on the entire surface of the Mueller-Hinton agar medium. After 3-5 min, aliquots of 


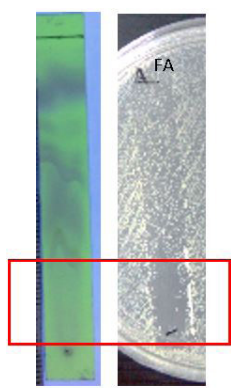

(a)

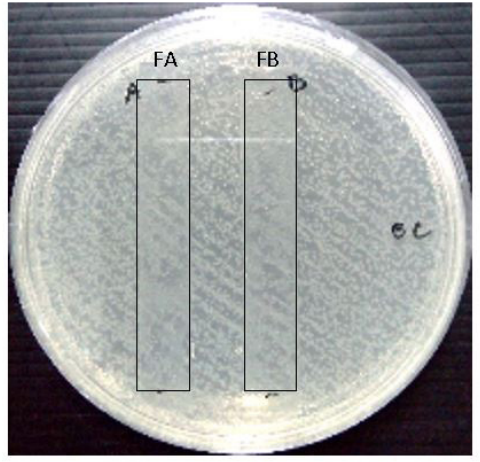

(e)

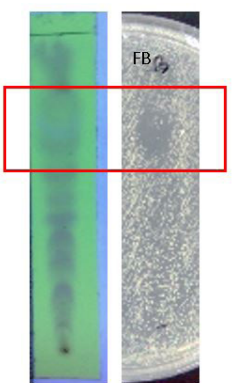

(b)

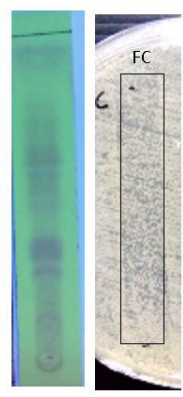

(c)

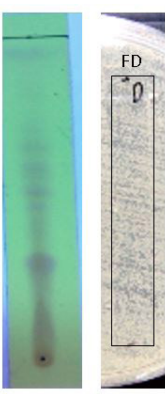

(d)

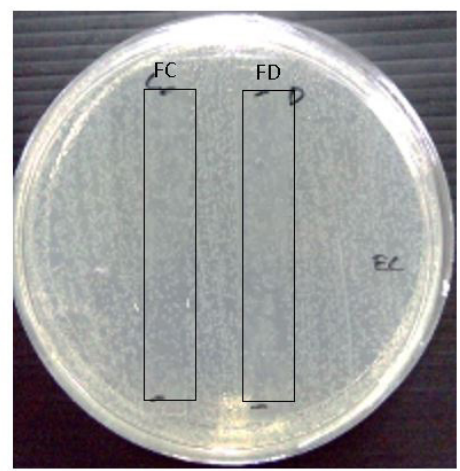

(f)

Figure 1. Bioautography results; (a) Fraction A against $S$. aureus; (b) Fraction B against $S$. aureus; (c) Fraction $C$ against $S$. aureus; (d) Fraction D against $S$. aureus; (e) Fractions $A$ and $B$ against $E$. coli; (f) Fractions $C$ and $D$ against $E$. coli

$20 \mu \mathrm{L}$ of each sub-fraction samples were pipetted on to filter paper disc of $6 \mathrm{~mm}$ diameter that had been placed on the surface of the media. Then they were incubated at $37^{\circ} \mathrm{C}$ for $18-24 \mathrm{~h}$. The chloramphenicol disc $30 \mu \mathrm{g} /$ disc (Oxoid) was used as a positive control and solvent (DMSO 10\%) was used as a negative control.

\section{GC-MS analysis of subfraction}

Active sub-fraction based on antibacterial activity testing was characterized by GC-MS analysis by injecting $5 \mu \mathrm{L}$ sample into HP Ultra 2 Capillary Column $(30 \mathrm{~m}$ x 0.2 $\mathrm{mm}$ i.d, $0.11 \mu \mathrm{m}$ film thickness) of GC-MS (Agilent Technologies 7890 Gas Chromatograph with autosampler and 5975 Mass Selective Detector and Chemstation Data System), with helium $(1.2 \mathrm{~mL} / \mathrm{min})$ used as a carrier gas. A temperature gradient program was applied with the initial temperature at $80^{\circ} \mathrm{C}$ hold for 0 minute, rising at $3{ }^{\circ} \mathrm{C} / \mathrm{min}$ to $150^{\circ} \mathrm{C}$, hold for 1 minute and finally rising $20^{\circ} \mathrm{C} / \mathrm{min}$ to $280^{\circ} \mathrm{C}$, hold for $26 \mathrm{~min}$. The resulting $\mathrm{m} / \mathrm{z}$ peaks (mass to charge ratio), which were characteristic of active sub-fractions, were compared to the spectrum library of corresponding organic compounds.

\section{RESULTS AND DISCUSSION}

\section{Identification of the Bacteria Strain}

The isolate of M2.Tnk.Bt $5.10^{-3} .2$ showed high homology to Vibrio sp. M-137-19 (99\% sequence similarity). Identification result that was carried out on M2.Tnk. Bt $5.10^{-3} .2$ confirmed several previous studies, which showed the predominance of Gram-negative bacteria in the marine environment and also reported $36 \%$ of Gramnegative bacteria as an antibiotic producer (Fenical, 1993; Bernen, 1997). Vibrio sp. bacteria show its dominance in marine ecosystems and some previous studies have shown this type of species to produce various types of secondary metabolites, which have antibacterial activity (Okada et al., 2005; Al-Zereini et al., 2010; Liaw et al., 2015).

\section{Antibacterial Activity}

The fractionation process by vacuum liquid chromatography produced 13 fractions, which were then monitored by Thin Layer Chromatography (TLC). Based on the same TLC separation pattern, 4 fraction combinations were obtained (FA, FB, FC and FD). 
Table 1. Antibacterial activity of sub-fractions

\begin{tabular}{lllllll}
\hline \multirow{2}{*}{ Sample } & \multirow{2}{*}{$\begin{array}{l}\text { Concentration } \\
(\boldsymbol{\mu g} / \text { disk) }\end{array}$} & \multicolumn{5}{c}{ Zone of Inhibition (mm) } \\
\cline { 3 - 7 } & $\mathbf{S A}$ & $\mathbf{B C}$ & $\mathbf{E F}$ & $\mathbf{E C}$ & VC \\
\hline SFr 1 & 18 & $7.65 \pm 0.35$ & $8.35 \pm 0.35$ & 0 & 0 & 0 \\
SFr 2 & 150 & $10.85 \pm 0.77$ & $8.75 \pm 0.92$ & $8.85 \pm 0.49$ & 0 & $10.3 \pm 1.13$ \\
SFr 3 & 38 & $10.95 \pm 2.05$ & $7.85 \pm 1.20$ & 0 & 0 & $10.55 \pm 0.63$ \\
SFr 4 & 10 & $9.6 \pm 0.28$ & $7.05 \pm 0.21$ & 0 & 0 & $11.9 \pm 1.13$ \\
SFr 5 & 24 & $10.7 \pm 1.13$ & $10 \pm 0.14$ & 0 & 0 & $11.9 \pm 2.54$ \\
SFr 6 & 20 & $7.45 \pm 1.06$ & $7.1 \pm 0.42$ & 0 & 0 & 0 \\
SFr 7 & 22 & $9.2 \pm 2.26$ & $8.85 \pm 2.75$ & 0 & 0 & $11.15 \pm 0.35$ \\
SFr 8 & 10 & $8.95 \pm 0.35$ & $8.55 \pm 1.48$ & 0 & 0 & 0 \\
SFr 9 & 14 & $9.35 \pm 0.92$ & $9.8 \pm 1.27$ & 0 & 0 & $9.55 \pm 1.20$ \\
SFr 10 & 28 & $9.1 \pm 1.41$ & $10.55 \pm 0.21$ & 0 & 0 & 0 \\
SFr 11 & 16 & $9.55 \pm 0.49$ & $9.9 \pm 0.42$ & 0 & 0 & $9.75 \pm 0.77$ \\
SFr 12 & 18 & $8.75 \pm 0.92$ & $11.25 \pm 0.63$ & 0 & $6.95 \pm 0.07$ & $10.1 \pm 0.56$ \\
SFr 13 & 12 & $9.2 \pm 0.28$ & $9.15 \pm 1.06$ & 0 & $6.75 \pm 0.35$ & $8.35 \pm 1.34$ \\
SFr 14 & 10 & $8.25 \pm 1.62$ & $7.2 \pm 0.56$ & 0 & 0 & $9.85 \pm 2.47$ \\
SFr 15 & 18 & $7.7 \pm 0.14$ & $7.8 \pm 0.70$ & 0 & 0 & $9.45 \pm 0.35$ \\
SFr 15A & 10 & $7.95 \pm 0.49$ & $8.5 \pm 0.42$ & 0 & 0 & 0 \\
SFr 16 & 12 & $8.9 \pm 1.98$ & $10.15 \pm 2.33$ & 0 & 0 & $11.15 \pm 0.49$ \\
CHL & 30 & $30.45 \pm 1.48$ & $21.35 \pm 0.70$ & $18.4 \pm 0$ & $23.05 \pm 1.48$ & $39.1 \pm 2.40$ \\
\hline
\end{tabular}

Results (shown as mean \pm SD), CHL (Chloramphenicol), SA (S. aureus), BC (B. cereus), EF (E. faecalis), EC (E. coli), VC (V. cholerae $)$

These fractions were further tested for antibacterial activity using bioautography (Fig 1). Bioautography is applied as the preliminary antibacterial assay in order to determine the presence or absence of activity (Choma \& GrZelak, 2011). In the preliminary screening, test strains (Staphylococcus aureus and Eschericia coli) were chosen to represent each group of Gram-positive bacteria and Gram-negative bacteria, respectively. The results showed the fraction $\mathrm{B}(\mathrm{FB})$ have antibacterial activity against $S$. aureus at $\mathrm{R}_{f}$ value (0.75). The fraction A (FA) also formed an inhibition zone against the $S$. aureus, but the $\mathrm{R}_{f}$ value could not be determined due to the separation pattern was not good enough on the TLC plate. Whereas against E. coli, no inhibition zone was formed for all fraction.

Based on the bioautography results, FB was chosen to be sub-fractionated further using HPLC semi-preparative. The separation process was achieved for $25 \mathrm{~min}$ and it obtained 17 sub-fractions (SFr 1 - SFr 16). The fractions obtained were evaluated to determine antibacterial activity using agar diffusion method (Table 1). The results of the antibacterial activity of 17 sub-fractions against Gram-positive bacteria showed the antibacterial activity that characterized by the formation of inhibitory zones in both $S$. aureus and B. cereus, but only sub-fraction of SFr 2 showed the inhibitory zone against E. faecalis. In the antibacterial activity assay of 17 sub-fractions against Gram-negative bacteria, not all sub-fractions showed activity against Gram-negative bacteria. Only sub-fraction of SFr 12 and SFr 13 showed inhibition activity against E. coli and 12 sub-fractions (SFr 2, SFr 3, SFr 4, SFr 5, SFr 7, SFr 9, SFr 11, SFr 12, SFr 13, SFr 14, SFr 15 and SFr 16) showed activity against $V$. cholerae.

The sub-fractions obtained were more active against Gram-positive bacteria than Gram-negative bacteria. This difference could be due to the cell wall structure of Gram-negative bacteria, which is more complex than that of Gram-positive bacteria, the membrane accumulation mechanisms in Gram-negative bacteria, or the mechanism of destruction of molecules introduced from the outside, that is caused by the presence of enzymes in the periplasmic space (Motamedi et al., 2010). Besides that, the difference results could be caused by different concentration from each sub-fractions.

\section{GC-MS Analysis}

The identification of sub-fraction SFr 2 was achieved by GC-MS to determine the type of compounds that produced antibacterial activity. SFr 2 was selected based on the yield that was more representative for analyzing further than other sub-fractions. Figure 2 


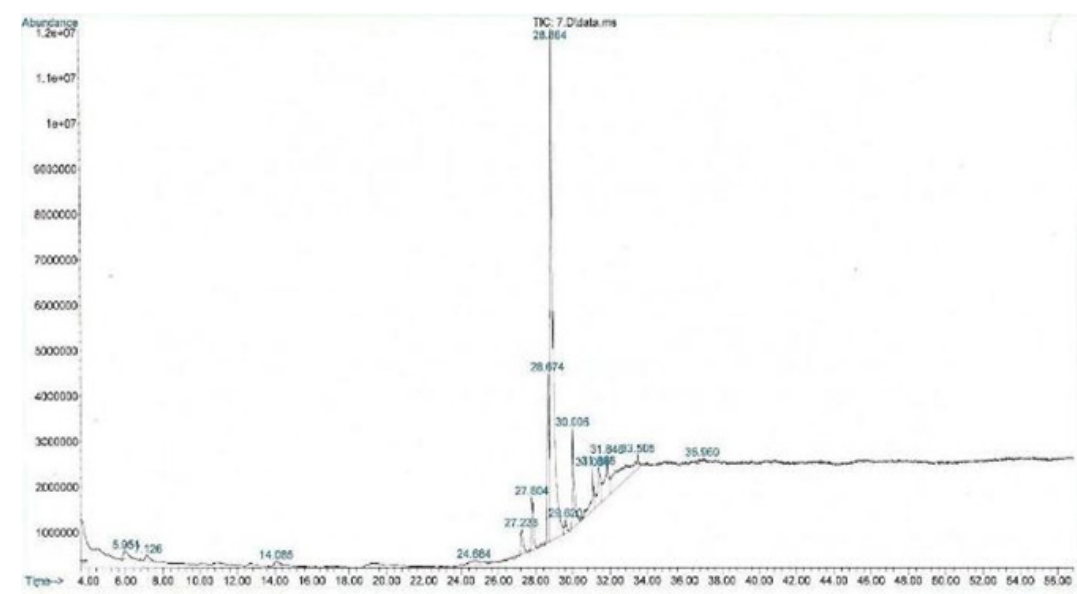

Figure 2. Gas chromatogram of SFr 2 profile

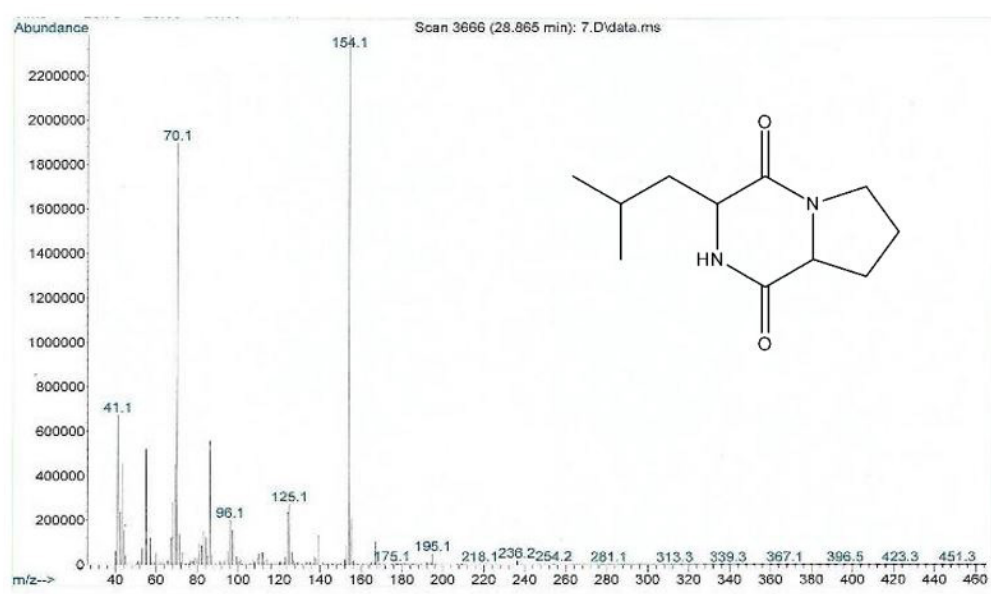

Figure 3. Chemical Structure and EI-MS spectrum of Pyrrolo [1,2-a] pyrazine-1,4-dione, hexahydro-3-(2 methylpropyl)

showed the chromatogram of SFr 2 with the dominant peak with the highest abundance at retention time of 28.864 min (peak area 48.34\%). Based on the GC-MS library record at that retention, it was confirmed that the molecular weight of the compound was 210 , and the molecular formula was determined as $\mathrm{C}_{11} \mathrm{H}_{18} \mathrm{~N}_{2} \mathrm{O}_{2}$, which was identified as Pyrrolo [1,2-a] pyrazine-1,4-dione, hexahydro-3- (2-methylpropyl) (PPDHMP). The EI-MS spectrum of SFr 2 indicated ions at $70\left(\mathrm{M}-\mathrm{C}_{7} \mathrm{H}_{10} \mathrm{NO}_{2}\right)$ and $154\left(\mathrm{M}-\mathrm{C}_{4} \mathrm{H}_{8}\right)$ (Fig 3). The fragmentation pattern of the spectrum has similarities to the EI-MS spectrum obtained in the previous study by Guo et al. (2015).

Based on the results, the PPDHMP was suggested as the main constituent of SFr 2 that could contribute to the antibacterial activity. This compound was previously isolated from Vibrio parahaemolyticus and from endophytic fungi Penicillium sp. (Fdhila et al., 2003; Pandey et al., 2010; Devi \& Wahab, 2012). Other chemical compounds detected by GC-MS were identified (Table 2). Some of the fatty acids with small quantities were tetradecanoic acid (1.26\%) and oleic acid (6.71\%), which have been reported to have antibacterial activity (Huang et al., 2010; Dilika et al., 2000; Yoon et al., 2018).

\section{CONCLUSION}

The secondary metabolite from Vibrio sp. shows promise as a potential source of the antibacterial compound. GC-MS analysis of the SFr 2 sub-fraction revealed the presence of fifteen phytochemical constituents with a major compound Pyrrolo [1,2-a] pyrazine-1,4dione, hexahydro-3- (2 methylpropyl). Isolation of pure compounds and optimization of the production of secondary metabolites should be carried out further.

\section{ACKNOWLEDGMENT}

This work was conducted by a grant from Indonesian Endowment Fund for Education (LPDP), Ministry of Finance of the Republic of Indonesia. 
Table 2. Phytochemicals of the SFr 2 sub-fraction

\begin{tabular}{|c|c|c|}
\hline Compound Identified & Retention Time (min) & Peak Area (\%) \\
\hline Phenol, 2-methoxy & 5.952 & 1.18 \\
\hline Propane, 2-chloro & 7.124 & 0.82 \\
\hline Phenol, 2,6-dimethoxy & 14.088 & 0.75 \\
\hline Benzoid acid, 4-hidroxy-3-methoxy & 24.686 & 2.02 \\
\hline Tetradecanoic acid & 27.238 & 1.26 \\
\hline 2-isopropyl-5-methylcyclohexamine & 27.803 & 3.87 \\
\hline Prolylleucyl anhydride & 28.672 & 9.79 \\
\hline $\begin{array}{l}\text { Pyrrolo [1,2-a] pyrazine-1,4-dione, } \\
\text { hexahydro-3-(2-metylpropyl) }\end{array}$ & 28.865 & 48.34 \\
\hline 9-octadecenoic acid (z) & 29.623 & 0.95 \\
\hline Oleic acid & 30.010 & 6.71 \\
\hline 9-octadecenoic acid (z) & 31.085 & 3.31 \\
\hline 8-hexadecenal, 14-methyl-, (z) & 31.389 & 4.44 \\
\hline $\begin{array}{l}1,8,15,22 \text {-tetraaza- } 2,7,16,21 \text {-cy- } \\
\text { clooctacosanetetrone }\end{array}$ & 31.851 & 4.85 \\
\hline $\begin{array}{l}\text { Pyridine-3-carboxamide, oxime, } \\
\text { N-(2-trifluoromethylphenyl) }\end{array}$ & 33.505 & 10.59 \\
\hline $\begin{array}{l}\text { 2-hydroxy-1-(hyroxymethyl) ethyl } \\
\text { (9z)-9-octadecenoate }\end{array}$ & 36.960 & 1.12 \\
\hline
\end{tabular}

\section{REFERENCES}

Al-Zereini, W., Yao, C. B. F. F., Laatsch, H., \& Anke, H. (2010). Aqabamycins A-G: novel nitro maleimides from marine Vibrio species: I. Taxonomy, fermentation, isolation, and biological activities. The Journal of Antibiotic, 63(6), 297-301.

Bernen, V. S., Greenstein, M., \& Maiese, W. M. (1997). Marine microorganism as a source of new natural products. Advances in apllied microbiology, vol 43 (pp. 57-90). New York: Academic Press.

Bugni, T. S., \& Ireland, C. M. (2004). Marine-derived fungi: a chemically and biologically diverse group of micro-organisms review. Natural Product Reports, 21(1), 143-163.

Choma, I. M., \& Grzelak, E. M. (2011). Bioautography detection in thin-layer chromatography. Journal of Chromatography A, 1218, 2684-2691.

CLSI. (2012). Perfomance standards for antimicrobial disk susceptibility test, approved standards, $11^{\text {th }} \mathrm{ed}$., CLSI document M02-A11. Wayne, Pennsylvania: Clinical and Laboratory Standards Institute.

Davidson, B. S. (1993). Ascidians: producers of amino acid-derived metabolites. Chemical Reviews, 93(5), 1771-1791.
Devi, N. N., \& Wahab F. (2012). Antimicrobial properties of endophytic fungi isolated from medicinal plant Camellia sinensis. International Journal of Pharma and Bio Sciences, 3(3), 420-427.

Dilika, F., Bremner, P. D., \& Meyer, J. J. (2000). Antibacterial activity of linoleic and oleic acids isolated from Helichrysum pedunculatum: a plant used during circumcision rites. Fitoterapia, 71(4): 450-452.

Ellis, G. A., Wyche, T. P., Fry, C. G., Braun, D. G., \& Bugni T. S. (2014). Solwaric Acids A and B, antibacterial aromatic Acids from a marine Solwaraspora sp. Marine Drugs, 12(2), 1013-1022.

Fdhila, F., Vazquez, V., Sánchez, J. L., \& Riguera. (2003). R. DD-diketopiperazines: antibiotics active against Vibrio anguillarum isolated from marine bacteria associated with cultures of Pecten maximus. Journal of Natural Products, 66(10), 1299-1301.

Fenical, W. (1993). Chemical studies of marine bacteria: developing a new resource. Chemical Reviews, 93(5), 1673-1683.

Guo, X., Liu, X., Pan, J., \& Yang, H. (2015). Synergitic algicidal effect and mechanism of two diketopiperazines produced by Chryseobacterium sp. strain GLY-1106 on the harmful bloom-forming Mycrocystis aeruginosa. Scientific Reports, 5, 14720. 
Huang, C, B., Altimova, Y., Myers, T. M., \& Ebersole, J. L. (2011). Short- and medium-chain fatty acids exhibit antimicrobial activity for oral microorganisms. Archives of Oral Biology, 56(7), 650-654.

Kjer, J., Debbab, A., Aly, A. H., \& Proksch, P. (2010). Method for isolation of marine-derived endophytic fungi and their Bioactive Secondary Products. Nature Protocols, 5(3), 479-490.

König, G. M., Kehraus, S., Seibert, S. F., Abdel-Lateff, A., \& Müller, D. (2006). Natural products from marine organisms and their associated microbes. ChemBioChem, 7(2), 229-238.

Liaw, C. C., Chen, P. C., Shih, C. J., Tseng, S. P., Lai, Y. M., Hsu, C. H., Dorrestein, P. C., \& Yang, Y. L. (2015). Vitroprocines, new antibiotics against Acinetobacter baumanni, discovered from marine Vibrio sp. QWI-o6 using mass-spectrometry-based metabolomics approach. Scientific Reports, 5, 12856.

Lupetti, A., Danesi, R., van't Wout, J. W., van Dissel, J., Senesi, T. S., \& Nibbering, P. H. (2002). Antimicrobial peptides: therapeutic potential for the treatment of Candida infections. Expert Opinion on Investigation Drugs, 11(2), 309-318.

Motamedi, H., Darabpour, E., Gholipour, M., \& Seyyednejad, S. M. (2010). Antibacterial effect of ethanolic and meyhanolic extract of Plantago ovata and Oliveria decumbens endemic in Iran against some pathogenic bacteria. International Journal of Pharmacology, 6(2), 117-122.

Nikapitiya, C. (2012). Bioactive secondary metabolites from marine microbes for drug discovery. In: Kim S-K (Ed.), Advances in Food and Nutrition Research (pp. 363-387). San Diego: Academic Press.

Okada, K., Lida, T., Kita-Tsukamoto, K., \& Honda, T. (2005). Vibrios commonly possess two chromosomes. Journal of Bacteriology, 187(2), 752-757.

Pandey, A., Naik, M. N., \& Dubey, S. K. (2010). Organic metabolites produced by Vibrio parahaemolyticus strain An3 isolated from Goan mullet inhibit bacterial fish pathogens. African Journal of Biotechnology, 9(42), 7134-7140.

Putra, M. Y., Murniasih, T., Wibowo, J. T., Hadi, T. A., Untari, F., Nisa, A. C., \& Swasono, R. T. (2016). Phenolic content, anti-oxidant, anti-plasmodium and cytotoxic properties of the sponge Acanthella cavernosa. Asian Pacific Journal of Tropical Disease, 6(10), 811-815.
Putra, M. Y., Murniasih, T., Swasono, R. T., Wibowo, J. T., Saputri, A. N. C., Widhiana, M. R., \& Arlyza, I. S. (2016). Secondary metabolites and their biological activities in Indonesian soft coral of the genus Lobophytum. Asian Pacific Journal of Tropical Biomedicine, 6(11), 909-913.

Schmidt, E. W., \& Donia, M. S. (2010). Life in cellulose houses: symbiotic bacterial biosynthesis of ascidians drugs and drug leads. Current Opinion in Biotechnology, 21(6), 827-833.

Smith, K. F., Goldberg, M., Rosenthal, S., Carlson, L., Chen, J., Chen, C., \& Ramachandran, S. (2014). Global rise in human infectious disease outbreaks. Journal of Royal Society Interface, 11(101), 20140950.

Valle Jr, D. L., Puzon, J. J. M., Cabrera, E. C., \& Rivera, W. L. (2016). Thin layer chromatography-bioautography and gas chromatography-mass spectrometry of antimicrobial leaf extracts from Philippine Piper betle L. against multidrug-resistant bacteria. Evidence-Based Complementary and Alternative Medicine, 1-7.

Viejo-Diaz, M., Andres, M. T., \& Fierro, J. F. (2005). Different anti-Candida activities of two human lactoferrin-derived peptides, Lfpep and kaliocin-1. Antimicrobial Agents Chemotherapy, 49(7), 2583- 2588.

Walsh, C. (2003). Where will new antibiotics come from?. Nature Reviews Microbiology, 1(1), 65-70.

Wyche, T. P., Hou, Y., Vazquez-Rivera, E., Braun, D., \& Bugni, T. S. (2012). Peptidolipins B-F: Antibacterial lipopeptides from an ascidian-derived Nocardia sp. Journal of Natural Products, 75(4), 735-740.

Yoon, B. K., Jackman, J. A., Valle-González, E. R., \& Cho, N-J. (2018). Antibacterial Free Fatty Acids and Monoglycerides: Biological Activities, Experimental Testing, and Therapeutic Applications. International Journal of Molecular Sciences, 19(4), 1114.

Zheng, L., Han, X., Chen, H., Lin, W., \& Yan, X. (2005). Marine bacteria associated with marine macroorganisms: the potential antimicrobial resources. Annals of Microbiology, 55(2), 119-124. 